\title{
Síndrome de lisis tumoral
}

\author{
Tumor lysis syndrome \\ Humberto Ochoa Salmorán, * Azucena Espinosa Sevilla, ${ }^{\ddagger}$ Rafael Hurtado Monroy ${ }^{\S}$
}

\section{Resumen}

El síndrome de lisis tumoral (SLT) es una complicación grave que se caracteriza por una elevada morbimortalidad y es secundaria a la liberación de componentes celulares a la circulación posterior a la lisis masiva de células malignas. Se produce desequilibrio hidroelectrolítico que puede desencadenar lesión renal aguda, arritmias y crisis convulsivas. Puede ocurrir en el primer ciclo de quimioterapia, o durante el tratamiento. EL SLT se asocia en la mayoría de los casos con quimioterapia citotóxica, aunque también se ha descrito con el uso terapéutico de anticuerpos monoclonales. Existen dos tipos: el SLT como síndrome clínico o sólo con cambios de laboratorio. EI SLT de laboratorio es más común y se define por aparición en 24 horas de dos o más alteraciones en electrolitos o ácido úrico. Para su diagnóstico se emplean los criterios de Cairo-Bishop y de Howard. Las medidas para prevenirlo incluyen monitoreo de laboratorio, uricosúricos y adecuada hidratación. La vigilancia con laboratorio se debe seguir durante el periodo de alto riesgo. La hidratación adecuada es lo principal para promover la excreción de ácido úrico y fosfato. Los hipouricemiantes como el alopurinol o agentes más nuevos como el febuxostat pueden ser efectivos. En años recientes se informa que el SLT es más frecuente con algunos de los nuevos agentes de tratamiento de la leucemia linfocítica crónica.

Palabras clave: Lisis, tumoral, quimioterapia.

\section{INTRODUCCIÓN}

El síndrome de lisis tumoral (SLT) es una complicación secundaria al uso de ciertos agentes quimioterápicos que compromete la vida del paciente, ocurre por la liberación a la circulación de componentes celulares posterior a la lisis masiva de células malignas. Su mortalidad varía entre 29 y 79\%. Cuando se reconoce temprano y se actúa de

\section{Abstract}

Tumor lysis syndrome (TLS) is a life-threatening complication secondary to the release to the blood of cellular components following the massive lysis of malignant cells. It can trigger acute kidney injury, arrhythmias and seizures. It usually occurs in the first cycle of chemotherapy, or throughout the treatment. It is associated in most cases with cytotoxic chemotherapy, but also by the use of therapeutic anti-CD20 monoclonal antibodies. There are two types: TLS manifested as a clinical syndrome or with laboratory changes. The TLS laboratory is more common, and it is defined by the appearance in 24 hours of two or more abnormalities in electrolytes or uric acid. For its diagnosis, the Cairo-Bishop and Howard criteria are used. The measures to prevent it include monitoring of laboratories, hypouricemiantes and adequate hydration. This follow-up with laboratories should be followed during the high-risk period. Adequate hydration is the most important measure, because it promotes the excretion of uric acid and phosphate. Hypouricemic agents such as allopurinol or newer agents such as febuxostat can be effective. The TLS has been observed frequently, although not severely, with some of the new treatment agents of chronic lymphocytic leukemia.

Keywords: Lysis, tumoral, chemotherapy.
* Médico Especialista en Medicina Interna y Terapia Intensiva, adscrito al Servicio de Urgencias.

* Médico Especialista en Medicina Interna y Nefrología, adscrito al Servicio de Urgencias.

$\S$ Médico Especialista en Hematología, Jefe del Departamento de Hematología.

www.medigraphic.com/actamedica
Hospital Ángeles Pedregal. Ciudad de México.

Correspondencia:

Humberto Ochoa Salmorán

Correo electrónico: hochoas2528@gmail.com

Aceptado: 16-10-2019.

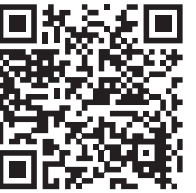


El SLT fue descrito por Bedrna y Polcák en 1929, pero hasta la década de los 80 se describió el síndrome clínico y analítico que ocurría en pacientes con linfoma de Burkitt. ${ }^{3}$ Se puede presentar durante el primer ciclo de quimioterapia o durante el tratamiento. Un tercio de los pacientes lo padecerá en ausencia de tratamiento citotóxico; se identifica como SLT espontáneo y SLT secundario. Se asocia en la mayoría de los casos con quimioterapia citotóxica, aunque también se ha descrito con el uso terapéutico de anticuerpos monoclonales (anti-CD20). ${ }^{1,3}$ También se informa posterior a la administración de radiación ionizante, embolización, ablación con radiofrecuencia, interferón y trasplante de células madre hematopoyéticas. ${ }^{4}$

\section{INCIDENCIA}

La incidencia ocurre entre 3 y $26 \%$ y se relaciona con los factores que se muestran en la Tabla 1. Los pacientes con tumores sólidos rara vez presentan SLT posterior al inicio

\section{Tabla 1: Factores de riesgo de} síndrome de lisis tumoral.

Alteraciones bioquímicas de laboratorio

- Hiperuricemia $>8 \mathrm{mg} / \mathrm{dL}$, hiperpotasemia e hiperfosfatemia, leucocitos $>100 \times 10^{9} / \mathrm{L}$, aumento de DHL inicial > $400 \mathrm{U} / \mathrm{L}$, nivel de creatinina inicial $>1.4 \mathrm{mg} / \mathrm{dL}$

En relación con la enfermedad

- Leucemia linfoblástica aguda, linfoma no Hodgkin tipo Burkitt, linfoma linfoblástico, tumores sólidos con alta tasa de crecimiento y con mayor sensibilidad a la quimioterapia: cáncer metastásico, cáncer de pulmón, carcinomas de esófago, gástrico y colorrectal, tumor del estroma gastrointestinal, hepatocarcinoma y el hepatoblastoma, carcinoma de mama, cáncer de endometrio y ovario, cáncer renal, meduloblastoma y neuroblastoma, melanoma y carcinoma de células de Merkel

- Enfermedades hematológicas con hiperleucocitosis, compromiso masivo de médula ósea y/o masas tumor voluminoso

En relación con el paciente

- Edad avanzada (>65 años), hepatoesplenomegalia, deshidratación

En relación con la función renal

- Lesión renal aguda o enfermedad renal crónica preexistente, diuresis $<1 \mathrm{~mL} / \mathrm{kg} / \mathrm{hora}$, uropatía obstructiva, compresión ureteral por tumor, infiltración del parénquima renal, $\mathrm{pH}$ urinario $<6$, hiponatremia

En relación con el tratamiento

- Esquemas con citarabina, compuestos de platino, glucocorticoides, menor incidencia con metotrexate, radioterapia y fármacos oncológicos no quimioterápicos, exposición a productos nefrotóxicos de la quimioterapia..$^{1-3}$ La diferencia de la incidencia entre las neoplasias hematológicas y sólidas se atribuye a la sensibilidad de la quimioterapia que se usa en los tumores sólidos, la heterogeneidad de éstos y el bajo índice de sospecha. ${ }^{3}$ El surgimiento y efectividad de las nuevas terapéuticas dirigidas a un amplio tipo de tumores aumentaron la incidencia del SLT. Entre los tratamientos nuevos destacan los inhibidores de la tirosina cinasa, los anticuerpos monoclonales, los agentes inmunomoduladores y los inhibidores de proteosomas. ${ }^{1,3}$

\section{FISIOPATOLOGÍA}

Cuando se produce destrucción celular, los componentes celulares que se liberan al torrente circulatorio desencadenan la producción de hiperuricemia, hiperpotasemia, hiperfosfatemia e hipocalcemia, este insulto primario excede la capacidad renal de su depuración, y provoca alteraciones hidroeléctricas y lesión renal aguda. ${ }^{3}$

La alteración más frecuente es la hiperuricemia, la cual puede precipitar lesión renal por nefropatía obstructiva que se explica porque los nucleótidos de ácidos nucleicos se metabolizan a hipoxantina por la xantino oxidasa y se convierten en xantina para terminar con la formación de ácido úrico, el cual de forma normal se elimina vía renal. En el SLT se supera la capacidad renal excretora y se acumula el ácido úrico, lo que por tanto produce hiperuricemia. Posteriormente el ambiente ácido de los túbulos colectores renales provoca que el ácido úrico se cristalice y precipite en la nefrona distal, lo que ocasiona obstrucción tubular y lesión renal aguda obstructiva. ${ }^{3,5,6}$

Las células neoplásicas tienen niveles altos de fosfato y cuando se liberan de manera secundaria a la lisis celular y disminuyen la eliminación renal, se presenta hiperfosfatemia. Ésta altera el equilibrio del calcio y fósforo, con lo cual el fosfato de calcio se cristaliza y precipita en la microcirculación y en los túbulos renales. Esto altera la filtración glomerular y es factor de daño de desarrollar lesión renal por nefropatía obstructiva a nivel tubular o por nefrocalcinosis. ${ }^{3,5}$

La hipocalcemia es secundaria a la hiperfosfatemia, que favorece la precipitación tubular de fosfato de calcio. Como factores coadyuvantes se observan niveles bajos de 1-25 dihidroxivitamina D3 y actividad ineficiente de la enzima renal 1 -alfa hidroxilasa. ${ }^{3}$ Sin embargo, la alteración más precoz y que expone la vida es la hiperpotasemia, que ocurre por la liberación celular de potasio así como la lesión renal. ${ }^{3-6}$

Por su parte, la lesión renal aguda tiene una incidencia de $25-38 \%$ y presenta dos mecanismos en su fisiopatología: el primero es la precipitación de fosfato de calcio, ácido úrico y xantina que provoca obstrucción tubular, nefrocalci- 
Tabla 2: Tipos de síndrome de lisis tumoral y criterios diagnósticos.

SLT de laboratorio*

- Ácido úrico: $>8 \mathrm{mg} / \mathrm{dL}$ o aumento de $25 \%$ respecto al basal. Potasio: $>6 \mathrm{mmol} / \mathrm{L}$ o aumento de $25 \%$ respecto al basal. Fósforo: $>4.5 \mathrm{mg} / \mathrm{dL}$ o aumento de $25 \%$ respecto al basal. Calcio corregido: $<7 \mathrm{mg} / \mathrm{dL}$ o aumento de $25 \%$ respecto al basal

SLT clínico ${ }^{\ddagger}$

- Creatinina: > 1.5 veces del límite normal superior con ajuste para la edad. Convulsiones. Arritmias. Muerte súbita

* SLT de laboratorio con dos o más criterios de laboratorio entre los tres días anteriores y los siete días posteriores al inicio de la quimioterapia. ${ }^{\ddagger}$ SLT clínico que presenta al menos una manifestación clínica acompañante o la muerte.

nosis y de forma secundaria hipocalcemia. La presencia de acidosis tubular contribuye a perpetuar la lesión renal.,3,5 El segundo mecanismo es vasoconstricción renal secundario al efecto proinflamatorio, oxidativo y activador del sistema renina-angiotensina así como la producción de citocinas, factor de necrosis tumoral (FNT) alfa, además de los efectos antiangiogénicos que actúan sobre el lecho vascular renal, lo que conduce a una nefropatía vasomotora y por último a un síndrome de respuesta inflamatoria sistémica con su expresión final y de más riesgo: falla orgánica múltiple. ${ }^{7}$

\section{TIPOS Y DIAGNÓSTICO DE SÍNDROME DE LISIS TUMORAL}

En 2004 Cairo-Bishop propuso la existencia de dos tipos de SLT y sus criterios diagnósticos (Tabla 2): 1. El que se manifiesta como síndrome clínico y 2. sólo con cambios de laboratorio. Aunque con importancia diagnóstica, la clasificación se limita a pronóstico al carecer de una clasificación con aceptación común que permita su reproducción con fines de comparación en diferentes estudios. La presentación con cambios de laboratorio es la más común. ${ }^{1,3,8} \mathrm{El}$ SLT clínico se caracteriza por un cambio agudo en los electrolitos séricos, cambios clínicos y complicaciones (náuseas, vómito, letargia, edema, lesión renal aguda, falla cardiaca congestiva y muerte súbita), por lo que representa una emergencia médica que requiere intervención inmediata. La gravedad se divide en cinco grados de acuerdo con las manifestaciones clínicas y de laboratorio (Tabla 3). ${ }^{1,8}$

Tanto en las recomendaciones de 2010 como en el trabajo de Howard y colaboradores en el año 2011 se propuso que un cambio en los resultados de laboratorio de $25 \%$ no era clínicamente importante hasta que éstos se encontraran fuera del rango de referencia, además se puede presentar primero una anormalidad en el laboratorio y posteriormente se agrega otra alteración en un tiempo no definido. Por lo anterior Howard y su equipo definieron el SLT como cambios en dos o más de los laboratorios en 24 horas. ${ }^{1,9}$

\section{FACTORES DE RIESGO Y ESTRATIFICACIÓN}

Se refiere a las alteraciones de laboratorio, características de la neoplasia del paciente, función renal previa y tratamiento citotóxico con el objetivo de categorizar a los pacientes de acuerdo con su riesgo y definir la terapéutica. Esta clasificación puede parecer compleja, pero resulta una guía pronóstica (Tabla 4). 3,7,10 La presencia de enfermedad renal preexistente y neoplasias hematológicas son un factor de riesgo independiente de mortalidad hospitalaria. Tendrán mayor riesgo de gravedad quienes presenten las siguientes

Tabla 3: Grados de síndrome de lisis tumoral.

\begin{tabular}{|c|c|c|c|c|}
\hline Grado & SLT de laboratorio & Creatinina & Arritmias & Convulsiones \\
\hline 0 & Ausente & 1.5 sobre el basal & - & - \\
\hline I & Presente & 1.5 sobre el basal & Intervención no indicada & - \\
\hline II & Presente & $\begin{array}{l}1.5-3.0 \text { sobre el } \\
\text { basal }\end{array}$ & Intervención no urgente & $\begin{array}{l}\text { Una, breve y generalizada, } \\
\text { controlada con antiepilépticos }\end{array}$ \\
\hline III & Presente & $\begin{array}{l}3.0-6.0 \text { sobre el } \\
\text { basal }\end{array}$ & $\begin{array}{l}\text { Arritmia sintomática, no } \\
\text { controlada o controlada } \\
\text { con desfibrilación }\end{array}$ & $\begin{array}{l}\text { Convulsiones con alteración } \\
\text { de conciencia }\end{array}$ \\
\hline IV & Presente & $>6.0$ sobre el basal & $\begin{array}{l}\text { Arritmia con fallo } \\
\text { cardiaco, hipotensión o } \\
\text { síncope }\end{array}$ & Estatus epiléptico \\
\hline V & Presente & Muerte & Muerte & Muerte \\
\hline
\end{tabular}


Tabla 4: Probabilidad de desarrollar síndrome de lisis tumoral.

\begin{tabular}{|c|c|c|c|}
\hline Tipo de neoplasia & Riesgo alto & Riesgo moderado & Riesgo bajo \\
\hline \multirow{4}{*}{$\begin{array}{l}\text { Linfoma de Hodgkin/no } \\
\text { Hodgkin }\end{array}$} & Linfoma de Burkitt & Linfoma de Burkitt & Linfoma indolente \\
\hline & Linfoma linfoblástico & Estadio temprano & Linfoma folicular \\
\hline & Estadio avanzado & $\mathrm{DHL}<2$ del valor normal & Linfoma MALT \\
\hline & $\begin{array}{l}\mathrm{DHL}>2 \text { del valor normal } \\
\text { Masa }>10 \mathrm{~cm} \text { en TC }\end{array}$ & Masa $<10 \mathrm{~cm}$ en TC & Linfoma de Hodgkin \\
\hline \multirow[t]{2}{*}{ Leucemia aguda linfoblástica } & Leucocitos > $100 \times 10^{9} / \mathrm{L}$ & Leucocitos $50 \times 10^{9} / \mathrm{L}$ & Leucocitos $<50 \times 10^{9} / \mathrm{L}$ \\
\hline & $\mathrm{DHL}>2$ del valor normal & $\mathrm{DHL}<2$ del valor normal & \\
\hline \multirow{2}{*}{$\begin{array}{l}\text { Leucemia aguda } \\
\text { mieloblástica }\end{array}$} & Leucocitos > $100 \times 10^{9} / \mathrm{L}$ & Leucocitos $25 \times 10^{9} / \mathrm{L}$ & Leucocitos $<25 \times 10^{9} / \mathrm{L}$ \\
\hline & & $\mathrm{DHL}>2$ del valor normal & $\mathrm{DHL}<2$ del valor normal \\
\hline \multirow{2}{*}{$\begin{array}{l}\text { Otras neoplasias } \\
\text { hematológicas }\end{array}$} & & Rápida proliferación celular & Leucemia linfocítica crónica \\
\hline & & $\begin{array}{l}\text { Buena respuesta a la } \\
\text { quimioterapia }\end{array}$ & Leucemia mieloide crónica \\
\hline \multirow[t]{4}{*}{ Neoplasias sólidas } & & Tumor voluminoso & \\
\hline & & Alta sensibilidad al & \\
\hline & & tratamiento citotóxico & \\
\hline & & $\mathrm{DHL}>2$ del valor normal & \\
\hline
\end{tabular}

Probabilidad de SLT: $1 \%$ en bajo riesgo, $1-5 \%$ en riesgo intermedio, mayor de $5 \%$ en riesgo alto.

características: ancianos, enfermedad renal preexistente, oliguria, acidez urinaria, deshidratación, esplenomegalia, hipotensión o cardiopatía previa. ${ }^{1,3,11}$

\section{MANIFESTACIONES CLÍNICAS}

EL SLT se manifiesta entre los días uno y tres de inicio de la quimioterapia, los síntomas son secundarios tanto a la enfermedad de base como las alteraciones de laboratorio. Las manifestaciones clínicas tales como anorexia, vómitos, diarrea, letargo, hematuria, oliguria y anuria se atribuyen a la hiperuricemia. 3,6

La hiperpotasemia provoca alteraciones en el músculo esquelético y cardiaco. Se manifiesta como taquicardia y fibrilación ventricular que constituyen una emergencia médica. Los cambios electrocardiográficos previos a estas arritmias incluyen ondas T "picudas", complejos QRS amplio, fusión del complejo QRS con la onda T. En la clínica se manifestará como fatiga, calambres musculares, anorexia, parestesias e irritabilidad. 3,6

La hiperfosfatemia leve a moderada es asintomática y es hasta que el fósforo alcanza niveles de gravedad, que se presenta con náuseas, vómitos, tetania, clínica neurológica (letargo, convulsiones) y arritmias cardiacas y todos estos síntomas se sobreponen con hipocalcemia, la cual se manifiesta de acuerdo con los valores de calcio iónico y de la velocidad de disminución. Los pacientes presentan espasmos carpopedales, laringoespasmos, tetania, convulsiones, coma, taquicardia ventricular polimórfica, muerte súbita, insuficiencia cardiaca, hipotensión arterial, pudiendo culminar en choque cardiogénico. ${ }^{3,6}$

\section{TRATAMIENTO PREVENTIVO Y DEL SLT ESTABLECIDO}

Las medidas para prevenirlo y tratarlo incluyen: monitoreo de laboratorios, uricosúricos, adecuada hidratación, mantener uresis, corrección de las alteraciones metabólicas y diálisis. La hospitalización se considera en pacientes de alto riesgo e incluso los más graves deben ingresar a una unidad de terapia intensiva, el grupo médico debe incluir: hematología y/u oncología médica, nefrología, medicina interna y medicina crítica. ${ }^{1-3,12}$

El objetivo del tratamiento preventivo es preservar la función renal, disminuir los niveles de ácido úrico, evitar sus manifestaciones clínicas y las alteraciones metabólicas de laboratorio. ${ }^{3}$ Esta vigilancia debe ser estrecha en el periodo de alto riesgo. Los estudios iniciales incluyen: biometría hemática completa con diferencial, panel metabólico, lactato deshidrogenasa, ácido úrico, fosfato, calcio ionizado, análisis de orina y es obligatorio un electrocardiograma. ${ }^{2} \mathrm{La}$ monitorización se individualiza para cada grupo de riesgo y se continuará 24 horas posteriores al término de la quimio- 
terapia o mientras persistan las alteraciones bioquímicas. Estas recomendaciones se aplican tanto a la quimioterapia clásica como a los nuevos medicamentos, a excepción de la administración de venetoclax, que requiere vigilancia durante cinco semanas así como cada seis u ocho horas cuando se administra y 24 horas posteriores a la indicación de cada dosis nueva. ${ }^{1,10}$

La hiperhidratación con cloruro de sodio $(\mathrm{NaCl})$ 0.9\% es crucial para prevenir y tratar el SLT, ya que promueve la excreción de ácido úrico y fosfato, previniendo la cristalización de éstos en los túbulos renales. ${ }^{1,3}$ El SLT de laboratorio se puede tratar de forma ambulatoria con la administración de líquidos vía oral y uricosúricos. La hidratación se indica en los grupos de bajo riesgo a moderado y en el grupo de alto riesgo se requiere hidratación intravenosa. La fluidoterapia se debe individualizar y se hará monitoreo hemodinámico para lograr dos objetivos; aporte de soluciones isotónicas de $2-3 \mathrm{~L} / \mathrm{m}^{2} /$ día y una diuresis > $1-2 \mathrm{~mL} / \mathrm{kg} /$ hora $\left(100 \mathrm{~mL} / \mathrm{m}^{2} / \text { hora) }\right)^{1-4,12-14}$ Cuando existe daño renal se debe mantener la hidratación para conservar un volumen intravascular adecuado que favorezca la uresis en metas por espacio de dos días. En caso de no lograr la meta a pesar de una hidratación adecuada y una valoración hemodinámica que concluya que el paciente no es respondedor a volumen y que se descartó uropatía obstructiva, debe considerarse el uso de diurético, que además es un tratamiento adyuvante para prevenir la sobrecarga hídrica. La dosis de furosemida es de $0.5-1 \mathrm{mg} /$ $\mathrm{kg} /$ dosis, como alternativas se recomienda manitol a 0.5-1 $\mathrm{g} / \mathrm{kg} /$ dosis y/o dopamina en infusión continúa a dosis de $2.5-5 \mu \mathrm{g} / \mathrm{kg} /$ minuto. En caso de no presentar respuesta al tratamiento será necesario considerar la diálisis. ${ }^{1,3}$

La hiperpotasemia se empeora por fármacos ahorradores de potasio, acidosis metabólica o falla renal. ${ }^{2}$ El tratamiento de la hiperpotasemia es crucial. Esta compilación se debe tratar en la unidad de cuidados intensivos, en especial con valores mayores de $6 \mathrm{mmol} / \mathrm{L}$, el tratamiento debe ser secuencial con bicarbonato, soluciones polarizantes, gluconato de calcio, furosemida y diálisis. Con valores menores de $6 \mathrm{mmol} / \mathrm{L}$ se indicará furosemida y resinas de intercambio. Los diuréticos pueden incrementar los niveles de ácido úrico, por tanto, se deberán emplear con cautela. ${ }^{1,3,12,13}$

Cuando los niveles de fosfato son mayores de $6 \mathrm{mg} /$ $\mathrm{dL}$ y el paciente se encuentra estable, se puede emplear hidróxido de aluminio 300-600 mg vía oral. En caso de hiperfosfatemia severa asociada a lesión renal se tratará con diálisis. Se favorecerá su excreción renal mediante la hidratación, rasburicasa y diurético. En casos leves o moderados se emplearán quelantes de fosfato como hidróxido de aluminio a dosis de 50-150 mg cada seis a ocho horas por dos días. 1,3,12,14,15
La hipocalcemia es secundaria al aumento de los niveles de fósforo, ya que se ligan y forman cristales de fosfato de calcio, los síntomas que pueden presentar los pacientes son anorexia, vómitos, crisis convulsivas y paro cardiaco. ${ }^{2}$ La hipocalcemia asintomática no se trata por el riesgo de precipitar cristales de calcio a nivel renal, sólo en caso de síntomas se administrará vía intravenosa un gramo de gluconato de calcio, el cual se podrá repetir hasta que los síntomas remitan. El control de la hiperfosfatemia previene la presencia de hipocalcemia secundaria. ${ }^{1-3}$

Los uricosúricos como el alopurinol o agentes nuevos como el febuxostat son efectivos en la prevención de la elevación del ácido úrico. Las dosis de alopurinol es 300 mg, dosis máxima de 800 mg, siempre que la función renal esté conservada. El alopurinol inhibe la formación de ácido úrico sin efecto uricolítico, su efecto se logra de 48 a 72 horas; por ello, se administra de dos a tres días antes de la quimioterapia y continúa de 10-14 días. Por este efecto lento, su utilidad en el SLT es limitada. El alopurinol reduce el riesgo de nefropatía por urato, aunque no tiene repercusión en la nefropatía por xantina, y para lograrlo es necesaria una hidratación intensa. Requiere ajuste de dosis en casos de daño renal y cuando se administra metotrexate o 6-mercaptopurina. Los efectos secundarios son hipersensibilidad, toxicidad cutánea grave, hepatotoxicidad e hipereosinofilia. ${ }^{1,3,4,10}$

El febuxostat es un inhibidor selectivo de la xantina oxidasa, no purínico, que favorece la eliminación del ácido úrico a nivel hepático, la dosis diaria es de 120 mg. Es una alternativa del alopurinol al no precisar ajuste de la dosis por daño renal así como la ausencia de los efectos secundarios del alopurinol y el mínimo riesgo de nefropatía por xantina. ${ }^{3}$ Estudios recientes informan que en el grupo de alto riesgo el febuxostat es superior al alopurinol. ${ }^{1}$

La National Comprehensive Cancer Network (NCCN) recomienda la rasburicasa en pacientes con alto riesgo en quienes la hidratación intensa no es factible o el alopurinol no es efectivo y en pacientes con daño renal agudo. Este fármaco es una enzima recombinante urato oxidasa (enzima proteolítica, ausente en el ser humano), que favorece el catabolismo del ácido úrico a alantoína, la cual es una sustancia no tóxica y más soluble que el ácido úrico en orina, no cristalizable en líquidos orgánicos y de fácil depuración renal, sin importar la tasa de filtrado glomerular. ${ }^{1,3,11}$ La dosis aprobada por la Food and Drug Administration (FDA) es $0.2 \mathrm{mg} / \mathrm{kg}$ diarios por cinco días, posteriormente una dosis de $0.15-0.2 \mathrm{mg} / \mathrm{kg}$, en caso de que los niveles de ácido úrico no disminuya se administrará una segunda dosis. Una dosis total de $5 \mathrm{mg}$ logra controlar los niveles de ácido úrico. ${ }^{1,10}$ La rasburicasa metaboliza el urato y el ácido úrico ya presente, y los disminuye de forma importante en más de $98 \%$ de los pacientes a las cuatro horas 
de su administración. También reduce la acumulación de hipoxantina y xantina, por lo que disminuye el riesgo de nefropatía tanto por urato como por xantinas. ${ }^{3,16} \mathrm{~A}$ pesar de su efectividad, no se han hecho suficientes ensayos clínicos aleatorios que muestren su efectividad en prevenir falla renal o muerte. ${ }^{1}$ En un estudio retrospectivo de Mitchell S. Cairo en 2016 se concluyó que el tratamiento con rasburicasa (26 pacientes) en comparación con alopurinol (104 pacientes) fue más efectivo en la reducción de los niveles plasmáticos de ácido úrico y disminuyó a la mitad los días de estancia en la unidad de cuidados intensivos así como los costos de los pacientes en hospitalización. 3,17 Se debe evitar en pacientes con asma o riesgo de hipersensibilidad. La rasburicasa se recomienda en pacientes con alto riesgo de desarrollar SLT con una dosis única de $3 \mathrm{mg}$ y se evalúa continuar el tratamiento de acuerdo con los valores de ácido úrico. Cuando se emplea se debe realizar la determinación de glucosa 6 fosfato deshidrogenasa, deficiencia ligada al $X$, por el riesgo de hemólisis grave y metahemoglobinemia. Estas complicaciones se reportaron en menos de $1 \%$ de pacientes que recibieron rasburicasa, de acuerdo con un estudio de la industria en 2011.1,3,10

El tratamiento de la hiperuricemia del SLT establecido con función renal conservada incluye hiperhidratación y rasburicasa, cuando hay datos de lesión renal se asociará diurético, en caso de refractariedad al tratamiento se debe considerar la diálisis. El alopurinol sólo se indica cuando el paciente tiene déficit de la enzima glucosa 6 fosfato deshidrogenasa, es decir, alérgico a la rasburicasa y deberá ajustarse a la función renal. La posología de la rasburicasa es $0.2 \mathrm{mg} / \mathrm{kg} /$ día en infusión intravenosa por 30 minutos. La duración del tratamiento varía de tres a siete días, dependiendo de la respuesta clínica y biológica. A pesar de su efecto importante al reducir los niveles de ácido úrico, no previene la lesión renal aguda, por lo que el resto del manejo se debe mantener. El riesgo de diálisis es de 1-4\% con el empleo de rasburicasa. Actualmente la alcalinización de la orina no es una terapéutica aceptada. ${ }^{1,3,10,12,14}$

La alcalinización de la orina no es tratamiento de elección, ya que se asocia con precipitación de cristales de fosfato de calcio. La diálisis está indicada cuando existe lesión renal aguda con alteraciones de electrólitos o del estado ácido base que exponga en riesgo la vida. 1,3,4

La diálisis es la terapia de elección en casos de SLT clínico establecido que no respondan a manejo conservador y de lesión renal aguda. La diálisis corrige las alteraciones metabólicas del síndrome, las indicaciones son: oliguria, alteraciones metabólicas refractarias al tratamiento, inestabilidad hemodinámica, lesión renal aguda, hipervolemia y como tratamiento de apoyo en caso de SLT espontáneo. El tratamiento con diálisis se debe realizar de forma precoz, pues un retraso en el tratamiento se asocia con peor respuesta y mayor mortalidad. La diálisis se deberá mantener hasta lograr revertir las alteraciones metabólicas, la normalización de la función renal y una diuresis sostenida. ${ }^{1,3,6}$

Los pacientes de riesgo moderado y alto deben ingresar en una unidad de cuidados intensivos durante 48-72 horas. La decisión de continuar el tratamiento o reducirlo se basará en la gravedad de las alteraciones del SLT y el estado clínico del paciente. Por otro lado, cuando se encuentran con daño renal o alteraciones metabólicas y éstas son secundarias a infiltración tumoral, se iniciará el tratamiento citotóxico específico. ${ }^{3,11,12}$

Con base en el grupo de riesgo se resume el tratamiento (Tabla 5). ${ }^{10}$

\section{EXPERIENCIA DE SLT CON NUEVOS AGENTES QUIMIOTERAPÉUTICOS}

Los nuevos agentes quimioterapéuticos tienen un diseño más específico en inducir una muerte celular de forma rápida en los casos de leucemia linfocítica crónica (LLC). La incidencia de SLT con los nuevos agentes quimioterapéuticos es variable y dependerá del fármaco así como de la neoplasia. Puede ocurrir con frecuencia con algunos de los nuevos agentes de tratamiento de la LLC como el ibrutinib. El riesgo de desarrollar SLT es menor con los anticuerpos monoclonales anti-CD-20 (rituximab, obinutuzumab y ofatumumab) como monoterapia o en asociación con otros. Se observa mayor frecuencia del SLT bioquímico con el inhibidor de serina/treonina quinasa (alvocidib) de forma hiperaguda requiriendo terapia de sustitución renal. En un análisis retrospectivo de 116 pacientes se encontró una incidencia de SLT de 46\%, la presencia de SLT no parece predecir la respuesta al tratamiento. La lenalidomida también se asocia con SLT como monoterapia y tiene una actividad modesta contra la LLC. 1,10

Se informa una incidencia menor de $5 \%$ con la administración de brentuximab vedotin, carfilzomib, dasatinib, lenalidomida y oprozomib. Por otro lado, en los casos de leucemia linfocítica crónica refractaria a tratamiento se presenta el SLT en más de 5\%. En la terapia con obinutuzumab y los pacientes con linfoma no Hodgkin se reporta una incidencia de SLT de $10 \%$ y los que se tratan con dinaciclib y diagnóstico de leucemia mieloide aguda o leucemia linfoblástica aguda la incidencia aumenta a $15 \%$. Al momento la mayor incidencia que se reporta es de 42 y 53\% cuando se emplea alvocidib en un régimen secuencial con citarabina y mitoxantrona en pacientes de bajo riesgo con leucemia mieloide aguda. ${ }^{10}$

Tanto el ibrutinib como el idelalisib tienen una excelente eficacia para el manejo de LLC, pero estos 
Tabla 5: Tratamiento de acuerdo con el grupo de riesgo.

\begin{tabular}{|c|c|c|c|c|c|c|}
\hline Riesgo & Laboratorios & Monitoreo & Hidratación & $\begin{array}{l}\text { Tratamiento de } \\
\text { ácido úrico }\end{array}$ & Control de fósforo & $\begin{array}{l}\text { Control de } \\
\text { potasio }\end{array}$ \\
\hline Ninguno & Nada & Nada & Nada & Nada & Nada & Nada \\
\hline Bajo & Diario & $\begin{array}{l}\text { Educación } \\
\text { al paciente } \\
\text { para acudir al } \\
\text { médico en caso } \\
\text { de intolerancia } \\
\text { a vía oral }\end{array}$ & $\begin{array}{l}\text { Hidratación vía } \\
\text { oral intensa, } \\
\text { o hidratación } \\
\text { intravenosa } \\
\text { asociada a la vía } \\
\text { oral }\end{array}$ & $\begin{array}{l}\text { Ninguno o } \\
\text { alopurinol vía } \\
\text { oral }\end{array}$ & Nada & $\begin{array}{l}\text { Evitar aporte } \\
\text { exógeno de } \\
\text { potasio }\end{array}$ \\
\hline Intermedio & $\begin{array}{l}\text { Cada 8-12 } \\
\text { horas }\end{array}$ & Hospitalización & $\begin{array}{l}\text { Líquidos } \\
\text { intravenosos } \\
\text { a razón de > } \\
2.5 \mathrm{~L} / \mathrm{m}^{2} / \text { día } \\
\text { monitorizando } \\
\text { diuresis y evitando } \\
\text { sobrecarga hídrica }\end{array}$ & $\begin{array}{l}\text { Alopurinol o } \\
\text { rasburicasa o } \\
\text { rasburicasa } \\
\text { continuada con } \\
\text { alopurinol }\end{array}$ & $\begin{array}{l}\text { Disminuir aporte } \\
\text { exógeno de } \\
\text { fósforo, quelantes } \\
\text { de fosfato si } \\
\text { fósforo está } \\
\text { elevado }\end{array}$ & $\begin{array}{l}\text { Evitar aporte } \\
\text { exógeno de } \\
\text { potasio }\end{array}$ \\
\hline Alto & $\begin{array}{l}\text { Cada 6-8 } \\
\text { horas }\end{array}$ & $\begin{array}{l}\text { Hospitalización, } \\
\text { monitoreo } \\
\text { cardiaco }\end{array}$ & $\begin{array}{l}\text { Líquidos } \\
\text { intravenosos a } \\
\text { razón de > } \\
2.5 \mathrm{~L} / \mathrm{m}^{2} / \text { día }\end{array}$ & Rasburicasa & $\begin{array}{l}\text { Disminuir aporte } \\
\text { exógeno de } \\
\text { fósforo, quelantes } \\
\text { de fosfato }\end{array}$ & $\begin{array}{l}\text { Evitar potasio } \\
\text { exógeno }\end{array}$ \\
\hline $\begin{array}{l}\text { SLT } \\
\text { establecido }\end{array}$ & $\begin{array}{l}\text { Cada 4-6 } \\
\text { horas }\end{array}$ & $\begin{array}{l}\text { Ingreso } \\
\text { a unidad } \\
\text { de terapia } \\
\text { intensiva }\end{array}$ & $\begin{array}{l}\text { Líquidos } \\
\text { intravenosos a } \\
\text { razón de > } \\
2.5 \mathrm{~L} / \mathrm{m}^{2} / \text { día }\end{array}$ & Rasburicasa & $\begin{array}{l}\text { Disminuir aporte } \\
\text { exógeno de } \\
\text { fósforo, quelantes } \\
\text { de fosfato }\end{array}$ & $\begin{array}{l}\text { Evitar potasio } \\
\text { exógeno }\end{array}$ \\
\hline
\end{tabular}

fármacos se asocian con un rápido decremento en el tamaño de los ganglios, en la linfocitosis así como en la demarginación; la presencia de SLT es más rara y aún no se ha logrado establecer los factores de riesgo de estos agentes. ${ }^{1}$

El venetoclax es un inhibidor potente y selectivo de la proteína antiapoptótica $\mathrm{Bcl}-2$ y se administra vía oral. Se reportan dos casos de SLT fatal en estudios recientes con la dosis de $50 \mathrm{mg}$ al día, seguidos de un esquema de tres semanas con una dosis total de 1,200 mg. Este proyecto inició estrategias de disminución de dosis para reducir el riesgo de SLT en los pacientes a quienes se administra este fármaco. ${ }^{1}$

\section{PRONÓSTICO}

La gravedad de las alteraciones metabólicas, la lesión renal e hidroelectrolíticas determinan el pronóstico. El SLT espontáneo así como los pacientes con lesión renal aguda son los que tienen un pronóstico más sombrío. La lesión renal aguda por sí misma es el factor más importante de mal pronóstico. $3,11,18,19$ En un estudio multicéntrico publicado en 2017 que incluyó 28,370 pacientes con SLT, la mortalidad hospitalaria fue de $21 \% .^{20}$

\section{CONCLUSIÓN}

Aunque el SLT puede ocurrir hasta en $26 \%$ de los casos en los que se hace el diagnóstico, convendrá considerar que podría ser mayor en quienes se ignora y la misma explicación aplicaría para la tasa de mortalidad.

La revisión que aquí se presenta propone actualizar los conceptos básicos del SLT para que su detección temprana permita reducir la morbimortalidad que ocasiona. El SLT es más frecuente por el uso de algunos medicamentos y de nuevos agentes terapéuticos para el tratamiento de las enfermedades hematooncológicas, aunque en los tumores sólidos no es raro.

Conflicto de intereses: Los autores niegan tener cualquier conflicto de intereses.

\section{REFERENCIAS}

1. Cheson BD, Heitner Enschede S, Cerri E, Desai M, Potluri J, Lamanna $\mathrm{N}$ et al. Tumor lysis syndrome in chronic lymphocytic leukemia with novel targeted agents. Oncologist. 2017; 22 (11):1283-1291.

2. Klemencic S, Perkins J. Diagnosis and management of oncologic emergencies. West J Emerg Med. 2019; 20 (2): 316-322.

3. Calvo-Villas JM. Síndrome de lisis tumoral. Med Clin. 2019; 152 (10): 397-304. 
4. Dubbs SB. Rapid fire: tumor lysis syndrome. Emerg Med Clin North Am. 2018; 36 (3): 517-525.

5. Davidson MB, Thakkar S, Hix JK, Bhandarkar ND, Wong A, Schreiber MJ. Pathophysiology, clinical consequences and treatment of tumor lysis syndrome. Am J Med. 2004; 116 (8): 546-554.

6. Hochberg J, Cairo M. Tumor lysis syndrome: current perspective. Haematologica. 2008; 93 (1): 9-13.

7. Soares M, Feres GA, Salluh JIF. Systemic inflammatory response syndrome and multiple organ dysfunction in patients with acute tumor lysis syndrome. Clinics (Sao Paulo). 2009; 64 (5): 479-481.

8. Cairo MS, Bishop M. Tumor lysis syndrome: new therapeutic strategies and classification. Br J Haematol. 2004; 127 (1): 3-11.

9. Howard SC, Jones DP, Pui CH. The tumor lysis syndrome. N Engl J Med. 2011; 364 (19): 1844-1854.

10. McBride A, Trifilio A, Baxter N, Gregory TK, Howard SC. Managing tumor lysis syndrome in the era of novel cancer therapies. J Adv Pract Oncol. 2017; 8 (7): 705-720.

11. Darmon M, Guichard I, Vincent F, Schlemmer B, Azoulay E. Prognostic significance of acute renal injury in acute tumor lysis syndrome. Leuk Lymphoma. 2010; 51 (2): 221-227.

12. Vasseur AS, Moreau AS. Analysis of the British guidelines 2015 for the management of adult tumor lysis syndrome. Reanimation. 2017; 26 (1): 285-295.
13. Dupré A, Mousseaux C, Bouguerba A, Ayed S, Barchazs J, Boukari $\mathrm{M}$ et al. Analysis of the 2015 British guidelines on the prevention and management of tumor lysis syndrome French. Rev Med Interne. 2017; 38 (1): 36-43.

14. Comité Nacional de Hematología. Guideline for management of tumor lysis syndrome. Arch Argent Pediatr. 2011; 109 (1): 77-82.

15. Will A, Tholouli E. The clinical management of tumour lysis syndrome in haematological malignancies: review. Br J Haematol. 2011; 154 (1): 3-13.

16. Lopez-Olivo MA, Pratt G, Palla SL, Salahudeen A. Rasburicase in tumor lysis syndrome of the adult: A systematic review and metaanalysis. Am J Kidney Dis. 2013; 62 (3): 481-492.

17. Cairo MS, Thompson S, Tangirala K, Eaddy MT. A clinical and economic comparison of rasburicase and allopurinol in the treatment of patients with clinical or laboratory tumor lysis syndrome. Clin Lymphoma Myeloma Leuk. 2017; 17 (3): 173-178.

18. Mughal TL, Ejaz A, Foringer JR, Coiffier B. An integrated clinical approach for the identification, prevention, and treatment of tumor lysis syndrome. Cancer Treat Rev. 2010; 36 (2): 164-176.

19. Wilson FP, Berns JS. Onco-nephrology: tumor lysis syndrome. Clin J Am Soc Nephrol. 2012; 7 (10): 1730-1739.

20. Durani U, Shah ND, Go RS. In-hospital outcomes of tumor lysis syndrome: a population based study using the national inpatient sample. Oncologist. 2017; 22 (12): 1506-1509. 